\title{
SHEAR BOND STRENGTH OF CERAMIC LAMINATE VENEERS TO ENAMEL AND ENAMEL-DENTINE COMPLEX BONDED WITH DIFFERENT ADHESIVE LUTING SYSTEMS
}

\author{
Nada H. Elkamhawy' $B D S$, Ahmed S. Elkadi² $P h D$, Fayza H. Alabbassy ${ }^{3} P h D$
}

\begin{abstract}
INTRODUCTION: The laminate veneer technique bonds a thin ceramic laminate to the tooth surface with resin cements to restore anterior teeth. A vital importance is attributed to the strength and durability of the adhesion complex.

OBJECTIVES: The aim of this study was to evaluate the shear bond strength of ceramic laminate veneers to two different tooth substrates (Enamel and Enamel-Dentine complex), with different luting systems.

MATERIALS AND METHODS: Sixty extracted human maxillary central incisor teeth were used, and randomly divided according to tooth surface preparations into two main groups (n=30); Group A in Enamel (E) only and Group B in Enamel-Dentin complex (E-D), each group was then subdivided according to the type of resin cement received (Light cure LC or Dual cure DC) into four sub groups of 15 specimens each: Group A 1:(E + LC); Group A 2:(E + DC); Group B 1:(E-D + LC); Group B 2:(E-D + DC). Ceramic discs (IPS e.max Press, IvoclarVivadent) of $4 \mathrm{~mm}$ in diameter and $2 \mathrm{~mm}$ in height were luted to the tooth surfaces by using the resin cement (Variolink Esthetic ${ }^{\mathbb{B}}$, IvoclarVivadent) according to the manufacturers' instructions. Shear bond strength test was performed in a universal testing machine at 0.5 $\mathrm{mm} / \mathrm{min}$ until bonding failure. Failure modes were determined under a stereomicroscope, and fracture surfaces were evaluated with a scanning electron microscope. The data were statistically analyzed $(\mathrm{p} \leq 0.05)$.

RESULTS: Group B 1 exhibited the lowest bond strength value( $9.12 \pm 4.86 \mathrm{MPa})$. There was statistically no difference among A 1 ,A 2 and among B 1,B 2(p>0.05). Group A 2 exhibited the highest bond strength value $(14.73 \pm 5.83 \mathrm{MPa})$.

CONCLUSIONS: The type of tooth substrate affected the shear bond strength of the ceramic laminate veneers to the 2 different types of tooth structures (Enamel, Enamel-Dentine complex).

KEYWORDS: Porcelain laminate veneers, ceramic discs, Dentine exposure, Adhesives.
\end{abstract}

Master student of Operative Dentistry, Department of Conservative Dentistry, Faculty of Dentistry, Alexandria University, Egypt.

Professor of Operative Dentistry, Department of Conservative Dentistry, Faculty of Dentistry, Alexandria University, Egypt.

Professor of Dental Biomaterials, Department of Dental Biomaterials, Faculty of Dentistry, Alexandria University, Egypt.

\section{INTRODUCTION}

The porcelain laminate veneer technique bonds a thin porcelain laminate to the tooth surface with dental adhesives and resin cements in order to restore discolored, worn, fractured, malformed, or slightly mal-positioned anterior teeth (1). For the longevity of the porcelain laminate veneers, a vital importance is attributed to the strength and durability of the adhesion complex formed between the three different components: the tooth surface, the resin cement, and the porcelain surface $(1,2)$.

Besides, many factors influence the long term success of the porcelain laminate veneers, such as structure of the tooth surface, preparation depth, type and thickness of the porcelain, type of the resin cement and dental adhesive, tooth morphology, and functional and para-functional activities $(1,3)$. Regarding preparation depth, enamel reduction, depending on location usually $0.3-0.7 \mathrm{~mm}$, is necessary to remove the aprismatic and hyper mineralized enamel top surface, which can be resistant to acid etching $(4,5)$.

It is reported that preparation should be mostly in enamel to maintain an optimal bond with the porcelain laminate veneers and to decrease the stresses in the porcelain $(4,6)$. Therefore, preparation technique becomes more important for the longevity of the porcelain laminate veneers because high failure rates of these restorations have been attributed to the large exposed dentine surfaces (7).
However the literature review lacks any in vitro study that has reported the effect of dentine exposure on the bond strength of the porcelain laminate veneers in the dental literature. Preparation for porcelain laminate veneers should be made meticulously to maintain the preparation as much as possible in enamel $(6,8)$.

However, exposure of considerable amounts of dentine is usually inevitable during the preparation, especially along the cervical and proximal areas $(9,10)$. Although improved new adhesives are developed, the bond strength of porcelain to enamel is still superior as compared to the bond strength of porcelain to dentine $(11,12)$.

Problems associated with bonding to dentine are more complicated to resolve than those associated with bonding to enamel because of the characteristics of the dentine substrates, which include lower inorganic content, tubular structure and variations in this structure, and the presence of outward intratubular fluid movement $(13,14)$.

One of the factors that play an important role in the long term outcome of porcelain laminate veneers is the adhesive system $(15,16)$.Another factor affecting optimal bonding between porcelain and the tooth structure is optimal curing of the resin cement $(15,17)$. Light curing resin cement is generally preferred by dentists for cementation of porcelain laminate veneers due to their color stability and longer working time as compared to dual- or chemical-curing resin cements $(15,17)$. 
Although clinical trials are the most suitable tools to evaluate the efficacy of the adhesive systems, long-term clinical trials are difficult to perform because of the time and rapid developments and changes in the adhesive systems. Therefore, laboratory studies are still largely used to predict the clinical behavior of dental materials (18). The laboratory tests most widely used to examine the bond strengths of the adhesive systems to dental hard tissues are shear and tensile bond strength tests (19).

The null hypotheses for this study were as follows: (i) There is no difference in the shear bond strength of the porcelain laminate veneers to enamel and enamel-dentin complex cemented with 2 different resin cements; (ii) The type of the adhesive system does not affect shear bond strength values; (ii) The type of the substrate of the prepared tooth affects shear bond strength values.

\section{MATERIALS AND METHODS}

Sixty extracted human maxillary central incisor teeth were used to evaluate \& compare shear bond strength of ceramic laminate veneers to enamel, enamel-dentin complex. Two different resin cements (light, dual cure) Variolink Esthetic ${ }^{\circledR}$ (Ivoclar Vivadent, Schaan, Liechtenstein) - and lithium disilicate glass-ceramic- IPS e.max Press (Ivoclar Vivadent, Schaan, Liechtenstein) - were selected for this study. The descriptions of the adhesives and the ceramic included in this study are summarized in (Table 1).

Table 1: Materials to be used in this study.

\begin{tabular}{|c|c|c|c|}
\hline $\begin{array}{l}\text { Brand } \\
\text { name }\end{array}$ & $\begin{array}{c}\text { Manufacture } \\
\mathbf{r}\end{array}$ & Composition & $\begin{array}{l}\text { Filler } \\
\text { loading }\end{array}$ \\
\hline $\begin{array}{c}\text { Variolin } \\
\mathbf{k} \\
\text { Esthetic } \\
\text { LC }\end{array}$ & $\begin{array}{c}\text { Ivoclar } \\
\text { Vivadent, } \\
\text { Schaan, } \\
\text { Liechtenstein }\end{array}$ & $\begin{array}{c}\text { Monomer matrix: } \\
\text { urethane } \\
\text { dimethacrylate } \\
\text { Inorganic fillers: } \\
\text { ytterbium } \\
\text { trifluoride } \\
\text { spheroid mixed } \\
\text { oxide } \\
\text { Initiatiors,Stabilize } \\
\text { rs } \\
\text { \& Pigments }\end{array}$ & $\begin{array}{c}38 \% \\
\text { inorgani } \\
\text { c fillers }\end{array}$ \\
\hline $\begin{array}{c}\text { Variolin } \\
\mathbf{k} \\
\text { Esthetic } \\
\text { DC }\end{array}$ & $\begin{array}{c}\text { Ivoclar } \\
\text { Vivadent, } \\
\text { Schaan, } \\
\text { Liechtenstein }\end{array}$ & $\begin{array}{c}\frac{\text { Monomer matrix : }}{\text { urethane }} \\
\text { dimethacrylate } \\
\text { Inorganic fillers: } \\
\text { ytterbium } \\
\text { trifluoride } \\
\text { spheroid mixed } \\
\text { oxide } \\
\text { Initiatiors, Stabilize } \\
\text { rs } \\
\text { \& Pigments }\end{array}$ & $\begin{array}{c}38 \% \\
\text { inorgani } \\
\text { c fillers }\end{array}$ \\
\hline $\begin{array}{l}\text { IPS } \\
\text { e.max } \\
\text { Press }\end{array}$ & $\begin{array}{c}\text { Ivoclar } \\
\text { Vivadent, } \\
\text { Schaan, } \\
\text { Liechtenstein }\end{array}$ & $\begin{array}{c}\mathrm{SiO} 2, \mathrm{Li} 2 \mathrm{O} \\
\mathrm{K} 2 \mathrm{O}, \mathrm{P} 2 \mathrm{O} 5 \\
\mathrm{ZrO} 2, \mathrm{ZnO} \\
\text { other oxides } \\
\text { colour oxides }\end{array}$ & \\
\hline
\end{tabular}

Selected teeth were free of caries, attrition, abrasion, cracking or previous restoration. The teeth were thoroughly washed with tap water, debrided from all soft tissues or bone, and stored in physiological saline at room temperature until use.

The root portion of all teeth was cut off, and the crown part was inserted into self curing acrylic resin using a custom made split metallic copper mold with a fixed diameter exposing the labial surface upwards. The 60 specimens were randomly divided according to tooth surface preparations into two main groups of 30 specimens each; Group A represented tooth surface preparation in enamel only and Group B represented tooth surface preparation in EnamelDentin complex, then each group was subdivided according to the type of adhesive resin cement used for cementation of the ceramic discs into four sub groups (Group A 1,A 2 and Group B 1,B 2) of 15 specimens each.

Facial surfaces of the teeth were initially prepared by placing depth-orientation grooves $(0.5 \mathrm{~mm}$ in depth) with a depth preparation bur. Then, the specimens were prepared without exceeding the depth-orientation grooves to provide flat enamel surface area, approximately $5 \mathrm{~mm}$ in diameter, for luting the ceramic discs to the middle third of the facial surface. In total, 30 teeth included for the enamel preparation. For the Enamel-Dentin complex preparations, facial surfaces of teeth were prepared with the same steps mentioned in the enamel group, until receiving flat enamel surface area then controlled preparations by grinding with silicon carbide abrasive papers of grit 100,400 , and 600 until dentine exposure occurred. Thus, the adhesion surfaces of the teeth were approximately half of the enamel and half of the dentine. In total, 30 teeth included for the enamel-dentine complex preparation. Finally the prepared labial surfaces were smoothened using a smooth sand paper disc (600- grit. Sic) under running water to obtain a flat surface for bonding procedures (20).

A total of 60 ceramic discs $(4 \mathrm{~mm}$ in diameter and $2 \mathrm{~mm}$ in height) were fabricated from IPS e.max press ceramic material. The discs were fabricated by the use of split metallic copper mold having the dimensions required for the test.

The ceramic discs were bonded to the prepared teeth according to the study design. Specimens of groups A 1, B 1 were cemented with light cure resin cement, while Specimens of groups A 2, B 2 were cemented with dual cure resin cement. The cementation was done under a constant load of $2.0 \mathrm{kgs}$ for five minutes using a special static loading device.

The bonded specimens were stored in distilled water at 37 ${ }^{\circ} \mathrm{C}$ for $24 \mathrm{~h}$ and were then thermocycled 500 cycles between 5 ${ }^{\circ} \mathrm{C}$ and $55{ }^{\circ} \mathrm{C}$ with a dwell time of 15 seconds at each temperature (16). All specimens were then subjected to shear bond strength test using universal testing machine (Comten Industries, INC., Florida, USA) with the stainless steel knife perpendicular to the junction between the tooth surface and ceramic disc at a cross head of speed $0.5 \mathrm{~mm} /$ minute until failure occurred. The fracture load was recorded and the shear bond strength was calculated in MPa.

The shear bond strength was calculated in $\mathrm{MPa}$ according to the following equation:

Shear bond strength $=$ fracture load $(\mathrm{Kg}) /$ surface area of the disc $\left(\mathrm{cm}^{2}\right)$

Where area of the disc $=\pi r^{2}$.

Then shear bond strength value in $\mathrm{Kg} / \mathrm{cm}^{2}$ was converted to MPa by multiplying with 0.09807 . 
To identify the failure mode of the specimens, following shear testing de-bonded adhesion surface samples were examined using:

- Stereomicroscope examination: All fractured de-bonded surface samples were examined at $2.5 \mathrm{x}$ magnification to identify the failure mode.

Possible failure modes were classified according to Scherrer et al. (2010) (21):

A. Adhesive failure between the ceramic and tooth surface within the bonding interface (less than $10 \%$ in the bonding area).

B. Cohesive failure in tooth structure and/or resin cement (more than $40 \%$ in the bonding area).

C. Mixed failure [Predominantly adhesive failure between the ceramic and tooth surface and/or resin cement or predominantly cohesive failure in tooth structure and resin cement (less than $40 \%$ in the bonding area)].

- Scanning electron microscopy examination (SEM): Representative specimens of each group were chosen to be further analyzed by SEM to determine the micro morphological topography. Specimens were sputtered by a coating of gold examined at accelerated voltage $15 \mathrm{Kv}$ and viewed at magnification $35 x$ and 1000x.

\section{STATISTICAL ANALYSIS}

Data were fed to the computer and analyzed using IBM SPSS software package version 20.0. ${ }^{(22,23)}$ Qualitative data were described using number and percent. Quantitative data were described using range (minimum and maximum), mean, standard deviation and median. Significance of the obtained results was judged at the $5 \%$ level.

The used tests were:

\section{Chi-square test}

For categorical variables, to compare between different groups.

2. Fisher's Exact or Monte Carlo correction

Correction for chi-square when more than $20 \%$ of the cells have expected count less than 5 .

3. Mann Whitney test

For abnormally quantitative variables, to compare between two studied groups.

\section{Kruskal Wallis test}

For abnormally quantitative variables, to compare between more than two studied groups.

5. Two way Univariate Analysis of Variance (ANOVA) was assessed to find the inter action between different factor effecting.

\section{RESULTS}

The highest mean bond strength was recorded in group A 2 (Enamel +Dual cure) $14.73 \pm 5.83 \mathrm{MPa}$, followed by group A 1 (Enamel +Light cure) $12.57 \pm 4.45 \mathrm{MPa}$, then group B 2 (Enamel-Dentin complex +Dual cure) $9.64 \pm 5.05 \mathrm{MPa}$, and the lowest mean bond strength was recorded in group B1(Enamel-Dentin complex +Light cure) $9.12 \pm 4.86 \mathrm{MPa}$ (Table 2).

By using Mann Whitney test and Kruskal Wallis test for statistical analysis to compare between studied groups, the effect of type of the adhesion surface (Enamel/EnamelDentin complex) within the specimens showed that Enamel surfaces provided higher bond strength than Enamel-Dentin complex surfaces. On comparing between Types of resin cement (light cure/dual cure) used in each subgroup, there was no statistically significant difference of the bond strength values between groups A 1 and A 2, and no statistically significant difference between groups B 1and B 2 ; However statistical significance was found between group A 1 and B 1 as well as between group A 2 and B 2 (Table 2).

Table 2: Comparison between the different studied groups according to shear bond strengths (MPa).

\begin{tabular}{|c|c|c|c|c|c|c|}
\hline & \multicolumn{2}{|c|}{ Enamel groups } & \multicolumn{2}{|c|}{$\begin{array}{c}\text { Enamel - } \\
\text { Dentin groups }\end{array}$} & \multirow[b]{2}{*}{${ }^{\mathrm{kw}} \chi^{2}$} & \multirow[b]{2}{*}{$\mathbf{p}$} \\
\hline & $\begin{array}{c}\text { (A1) } \\
\text { Light } \\
\text { cure } \\
(\mathrm{n}= \\
15)\end{array}$ & $\begin{array}{l}(\mathrm{A} 2) \\
\text { Dual } \\
\text { cure } \\
(\mathrm{n}= \\
15)\end{array}$ & $\begin{array}{c}\text { (B1) } \\
\text { Light } \\
\text { cure } \\
(n= \\
15)\end{array}$ & $\begin{array}{c}\text { (B2) } \\
\text { Dual } \\
\text { cure } \\
(n= \\
15)\end{array}$ & & \\
\hline $\begin{array}{l}\text { Shear bond } \\
\text { strengths } \\
\text { Min. - } \\
\text { Max. }\end{array}$ & $\begin{array}{l}6.44- \\
22.27\end{array}$ & $\begin{array}{l}5.55- \\
23.35\end{array}$ & $\begin{array}{l}4.80- \\
21.61\end{array}$ & $\begin{array}{l}4.85- \\
21.32\end{array}$ & & \\
\hline $\begin{array}{c}\text { Mean } \pm \\
\text { SD. } \\
\text { Median }\end{array}$ & $\begin{array}{c}12.57 \pm \\
4.45 \\
\\
11.71\end{array}$ & $\begin{array}{c}14.73 \pm \\
5.83 \\
14.58\end{array}$ & $\begin{array}{c}9.12 \pm \\
4.86 \\
8.88\end{array}$ & $\begin{array}{c}9.64 \pm \\
5.05 \\
8.88\end{array}$ & $12.099^{*}$ & 0.007 \\
\hline $\mathbf{p}_{1}$ & & & & & & \\
\hline $\mathbf{p}_{2}$ & & & $0.025^{*}$ & $0.013^{*}$ & & \\
\hline
\end{tabular}

${ }^{\mathrm{KW}} \chi^{2}$ : Chi square for Kruskal Wallis test, Sig. bet. grps was done using Mann Whitney test

$\mathrm{p}_{1}$ : $\mathrm{p}$ value for comparing between $\mathrm{A} 1$ and $\mathrm{A} 2, \mathrm{~B} 1$ and $\mathrm{B} 2$ $\mathrm{p}_{2}$ : $\mathrm{p}$ value for comparing between $\mathrm{A} 1$ and $\mathrm{B} 1, \mathrm{~A} 2$ and $\mathrm{B} 2$

$*$ : Statistically significant at $p \leq 0.05$

Thus, the type of the adhesion surface (Enamel/EnamelDentin complex) alone revealed statistically significant effect on the shear bond strength values of the groups $(p \leq 0.05)$.

Comparison between the different studied groups according to stereomicroscope results (Table.3) demonstrated:

In group A 1 (Enamel + Light cure) fourteen specimens showed mixed pattern of failure where four of them being predominantly cohesive $(26.7 \%)$ while the other ten showed predominantly adhesive pattern $(66.7 \%)$, While only one specimen showed cohesive pattern of failure $(6.7 \%)$.

While In group A 2 (Enamel + Dual cure) eleven specimens showed mixed pattern of failure where three of them being predominantly cohesive $(20 \%)$ while the other eight being predominately adhesive $(53.3 \%)$, while four specimens showed cohesive pattern of failure (26.7\%) (Fig. $1 \mathrm{a}, \mathrm{b}, \mathrm{c}$ ). There was no statistically significant difference between the two groups.

In group B 1 (Enamel-Dentin + Light cure) eleven specimens showed mixed pattern of failure where four of them being predominantly cohesive $(26.7 \%)$ while the other seven being predominately adhesive $(46.7 \%)$, while four specimens showed cohesive pattern of failure (26.7\%).

While In group B 2 (Enamel-Dentin + Dual cure) thirteen specimens showed mixed pattern of failure where six of them being predominantly cohesive $(40 \%)$ while the other seven being predominately adhesive $(46.7 \%)$, while Two specimens showed cohesive pattern of failure (13.3\%) (Fig.2 a, b, c). There was no statistically significant difference between the two groups. 
Table (3): Comparison between the different studied groups according to stereomicroscope results.

\begin{tabular}{|c|c|c|c|c|c|c|c|c|c|c|c|c|}
\hline \multirow{3}{*}{ Stereomicroscope results } & \multicolumn{4}{|c|}{ Enamel groups } & \multicolumn{4}{|c|}{ Enamel - Dentin groups } & \multirow{3}{*}{ Total } & \multirow{3}{*}{$\%$} & \multirow{3}{*}{$\chi^{2}$} & \multirow{3}{*}{${ }^{\mathrm{MC}} \mathbf{p}$} \\
\hline & \multicolumn{2}{|c|}{$\begin{array}{c}\text { (A1) } \\
\text { Light cure } \\
(\mathrm{n}=15)\end{array}$} & \multicolumn{2}{|c|}{$\begin{array}{c}\text { (A2) } \\
\text { Dual cure } \\
(n=15)\end{array}$} & \multicolumn{2}{|c|}{$\begin{array}{c}\text { (B1) } \\
\text { Light cure } \\
(\mathrm{n}=15)\end{array}$} & \multicolumn{2}{|c|}{$\begin{array}{c}\text { (B2) } \\
\text { Dual cure } \\
(\mathrm{n}=\mathbf{1 5})\end{array}$} & & & & \\
\hline & No. & $\%$ & No. & $\%$ & & $\%$ & No. & $\%$ & & & & \\
\hline Cohesive & 1 & 6.7 & 4 & 26.7 & 4 & 26.7 & 2 & 13.3 & 11 & 18.3 & & \\
\hline Mixed & & & & & & & & & & & & \\
\hline P. Cohesive & 4 & 26.7 & 3 & 20.0 & 4 & 26.7 & 6 & 40.0 & 17 & 28.3 & 4.259 & 0.669 \\
\hline P. adhesive & 10 & 66.7 & 8 & 53.3 & 7 & 46.7 & 7 & 46.7 & 32 & 53.3 & & \\
\hline${ }^{\mathrm{MC}} \mathbf{p}_{1}$ & \multicolumn{4}{|c|}{0.456} & \multicolumn{4}{|c|}{0.579} & & & & \\
\hline${ }^{\mathrm{MC}} \mathbf{p}_{2}$ & & & & & \multicolumn{4}{|c|}{0.470} & & & & \\
\hline
\end{tabular}

$\chi^{2}$ : Chi square test

MC: Monte Carlo for Chi square test for comparing between different groups and each two groups $p_{1}$ : $p$ value for comparing between $\mathrm{A} 1$ and $\mathrm{A} 2, \mathrm{~B} 1$ and $\mathrm{B} 2$ $\mathrm{p}_{2}$ : $\mathrm{p}$ value for comparing between $\mathrm{A} 1$ and $\mathrm{B} 1, \mathrm{~A} 2$ and $\mathrm{B} 2$

*: Statistically significant at $\mathrm{p} \leq 0.05$

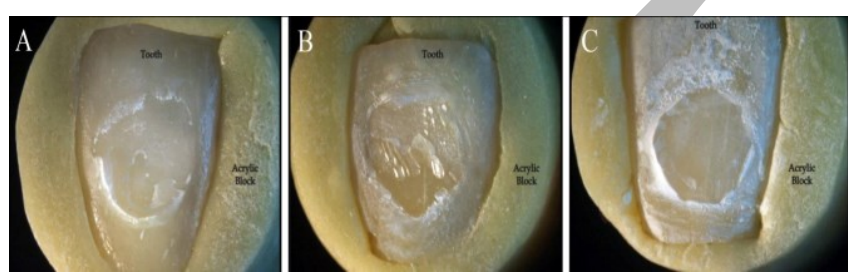

Fig. (1): Stereomicroscope images demonstrating mode of failure in Enamel groups showing: A. Cohesive pattern of failure, B. Mixed pattern of failure (predominantly cohesive), C. Mixed pattern of failure (predominantly adhesive).

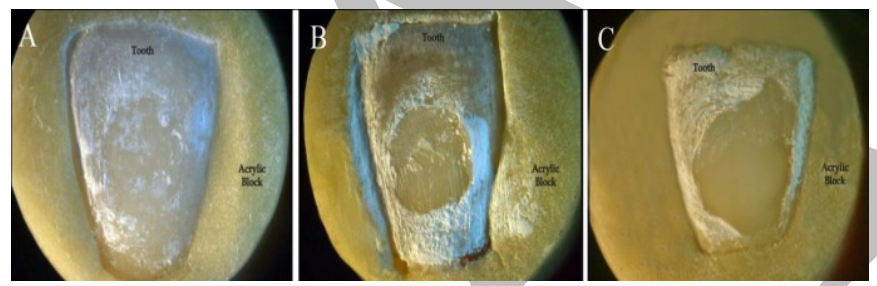

Fig. (2): Stereomicroscope images demonstrating mode of failure in Enamel-Dentin complex groups showing : A. Cohesive pattern of failure, B. Mixed pattern of failure (predominantly cohesive), C. Mixed pattern of failure (predominantly adhesive).

Therefore, through SEM analysis it was confirmed that the most frequent pattern of failure was mixed predominantly adhesive failures. Predominantly adhesive failures were more likely to occur between the tooth substrate and porcelain rather than between resin cement and porcelain showing very small amounts of adhesive resin on the tooth surface (less than $10 \%$ of the bonding area) (Fig. 3a).Furthermore, it was found that most of the dentinal tubules were covered with the dentine adhesives (Fig. 3b).

The following most frequent fracture pattern is Mixed predominantly cohesive failure, This type of failure designates a mixture of adhesive failure and cohesive failure (less than $40 \%$ of the bonding area) within the same fracture surface with the predominance of cohesive failure (Fig 4 $a, b)$.
An example of a cohesively fractured sample is presented in (Fig 5 a,b). The cohesive failures occurred (more than $40 \%$ of the bonding area) with remaining resin cement on the tooth substrate.
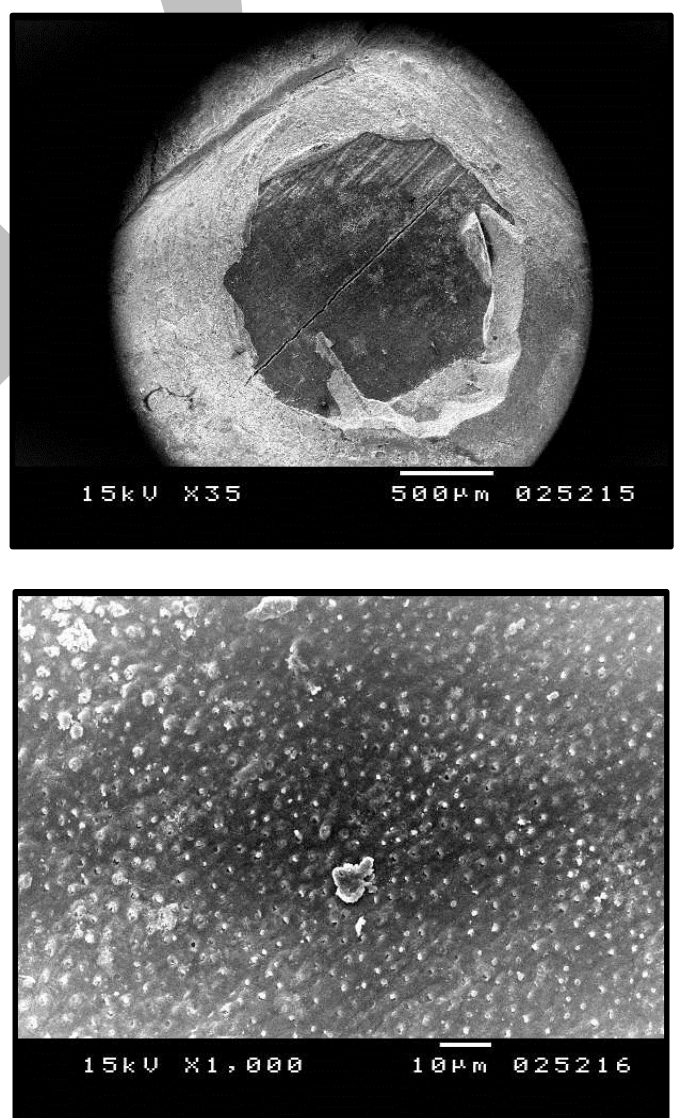

Fig. (3): (a, b) Mixed Predominantly Adhesive Failure (Resin tags where most of the dentinal tubules are covered with dentin adhesives). 

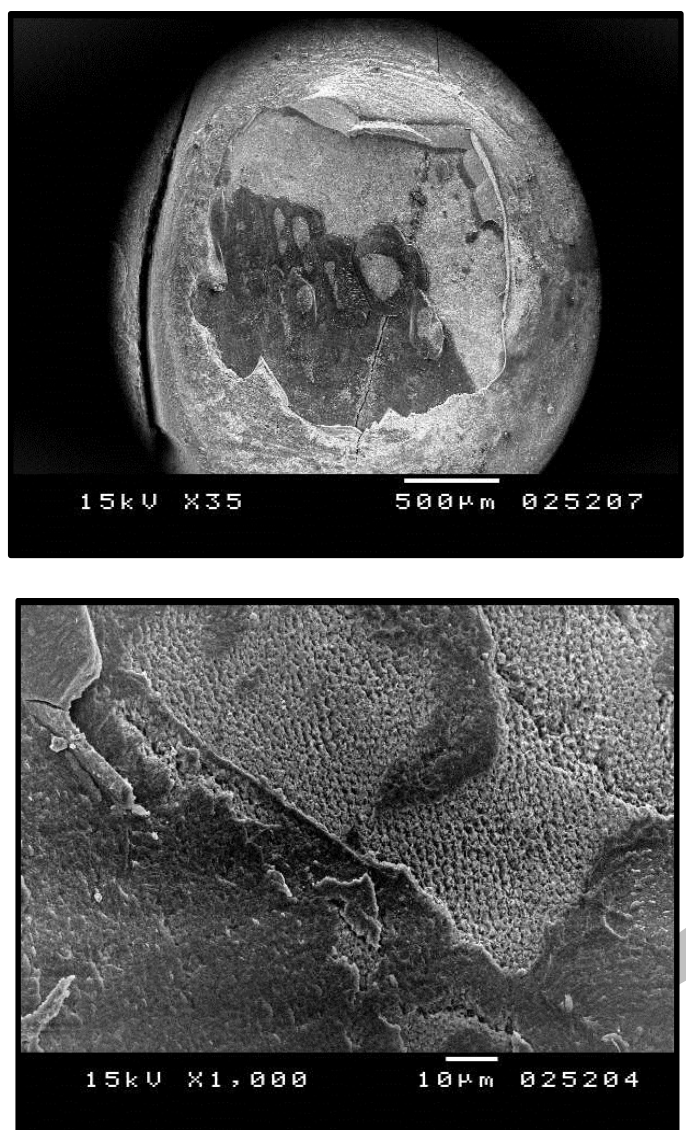

Fig. (4): SEM micrographs of mixed predominantly cohesive failure $(\mathrm{a}, \mathrm{b})$ Mixed Predominantly Cohesive Failure.
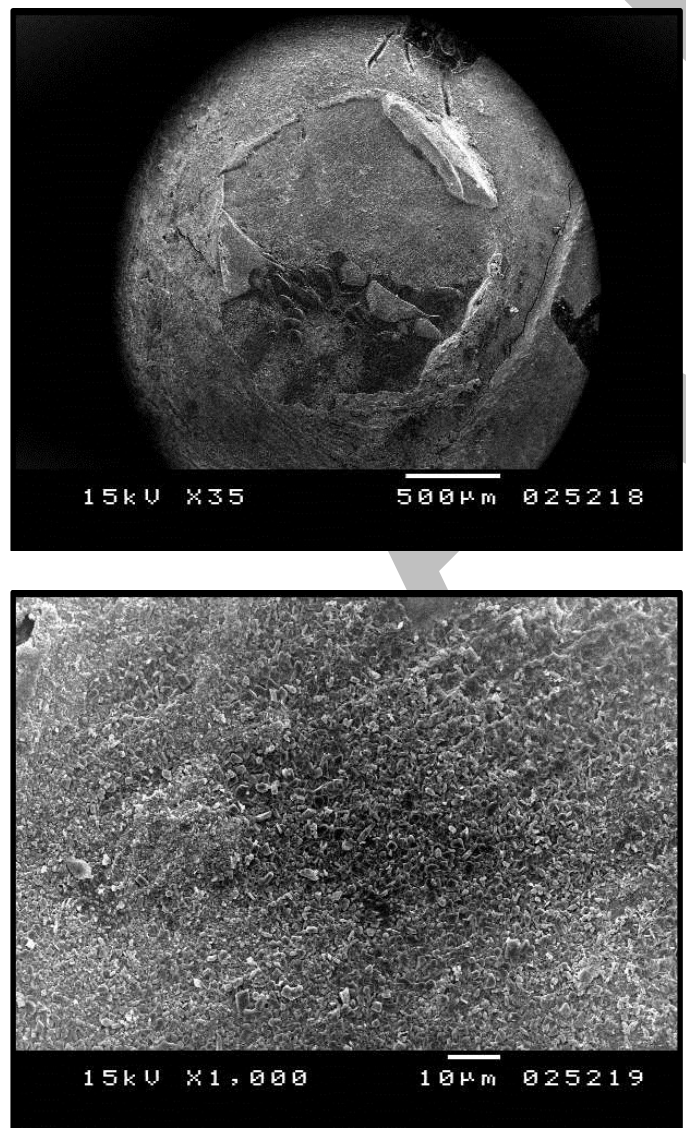

Fig. (5): SEM micrographs of cohesive failure $(a, b)$ Cohesive Failure.

\section{DISCUSSION}

One of the ways in which clinicians select products for their practices is by comparing the products' performances in vivo and in vitro studies (24). Although in vivo trials are the ultimate tests to evaluate the performance of the adhesive systems, too many variables involved make it difficult to differentiate the true reason for failure (25).

A requirement for successful function of ceramic restorations over years is its adequate adhesion to tooth structure; bond strengths are influenced by several factors as surface treatments (type of etchant and its concentration) and more important is the luting cement type (26,27). Bonding of ceramics to tooth structure is based on adhesion of the luting cement and its bonding resin to the ceramic substrate together with adhesion of the luting cement to enamel and dentin (27).

The results of the present study support the rejection of the first null hypothesis that there is no difference in the shear bond strength of ceramic laminate veneers to enamel, and enamel-dentine complex cemented with 2 different resin cements. Within the Enamel groups, no significant differences between the 2 cements were found. Although, Enamel-dentine groups showed no statistically significant difference among themselves, Enamel-dentin complex groups exhibited lower shear bond strength values than the enamel groups as obtained from (Table 2); from which it was concluded that the type of adhesion surface (Enamel / Enamel-Dentin complex) had the highest effect on shear bond strength values.

In agreement with the present study results, Abo-Hamar et. al (28), Öztürk et. al (20) and Bair et. al (29) reported that the type of the tooth substrate in terms of enamel and dentine affected the bond strength of the tested luting resin cements; with relatively low bond strength to dentin than to enamel. Since, dentin is an inherently wet tissue adhesion to dentin can be difficult which is affected by several factors related to dentin bonding; including the higher organic content of dentin, fluid pressure from dentinal tubules, and the presence of a smear layer (30).

While, this is in contradiction to what was found by Lafuente et. al (31) who evaluated the bonding effectiveness of four different resin luting cements to enamel and dentin, significant differences were found among resin cements, independent of the type of tooth substrate that had no effect on the bond strength values. This could be explained because the test used was tensile bond strength which is different than the test used in the current study.

However, bonding of the ceramic restorations to enamel is still superior as compared to bonding to Enamel-dentine complex, although developments in adhesive systems were made. This is promising for future researches in terms of developing the bond strength of ceramics to dentine.

The results of this study demonstrated that the effect of the type of preparation surface on shear bond strength was much higher than the effect of the resin cement type, according to the results of the statistical analysis of the tested resin cements, in which there was no significant difference between the two different resin cements on comparing between groups of same tooth substrate. No statistical significance was found between groups A 1 and A2 as well as between groups B1 and B 2 .

Thus, the second null hypothesis can be accepted. In agreement with the findings of Hikita et. al (32), it can be said that light-curing resin cements performed as well as 
dual curing resin cements within the limitations of this study.

In the present study, the type of preparation surface had a significant effect on the shear bond strength. When the two analyzed tooth surfaces were compared, there was significant difference between the enamel and enamel-dentine complex groups (Table.2).

Therefore, the results support the third null hypothesis that the type of the substrate of the prepared tooth affects shear bond strength values. It has been reported that shear bond strength of adhesives to dentine should be at least 17 $\mathrm{MPa}$ and to enamel should be at least $20 \mathrm{MPa}$ to adequately compensate for the stresses caused by polymerization shrinkage to the composite resin $(33,34)$.

According to the results of this study, mean shear bond strength values of the enamel was within a range of (14.73 $\pm 5.83 \mathrm{MPa}-12.57 \pm 4.45 \mathrm{MPa})$. However, mean shear bond strength values of the Enamel-dentine groups were reported in a range of $(9.64 \pm 5.05 \mathrm{MPa}-9.12 \pm 4.86 \mathrm{MPa})$. In this case, even if dentine exposure occurs during the preparation, ceramic laminate veneers can exhibit a durable bond between the tooth surface and ceramic in the presence of enough enamel, which should be at least half of the prepared surface in relation to the results of this study (20).

However, the more the dentine is exposed, the weaker the shear bond strength of the porcelain. Therefore, it has been suggested that for ceramic laminate veneer restorations, all preparation margins should be in sound enamel (35).

Furthermore, Magne and Douglas (36) reported that with the proper use of dentine adhesives, teeth restored with ceramic laminate veneers can exhibit mechanical behavior similar to that of intact teeth. Until now, no effort has been made on assessing the shear bond strength of ceramic veneers when dentine is exposed cervically during preparation; since this area is difficult in isolation as well as bonding procedures.

Classification of the failure modes in this study was similar to the classification of failure modes reported by Scherrer et. al (21). All of the mixed failures included tooth substrate and resin cement partially being (less than $40 \%$ ) of the total adhesion area. All cohesive failures were seen in the tooth substrate, when the fractured tooth substrate was in large portions $(40 \%>)$, it was classified as cohesive failure. When the failure occurred in adhesion between the tooth substrate and the bonded material, it is described as adhesive failure even if we observed very small amounts of adhesive resin on the tooth surface $(10 \%<)$.

In the present study, on analyzing the failure modes according to the previously mentioned classification, it was recorded that the frequent pattern of failure was Adhesive followed by mixed predominantly cohesive followed by cohesive failure. All of the mixed or cohesive failures were in the tooth and/or cement, rather than the ceramic material. This interfacial failure with minimal cohesive fractures in dentine and/or resin may be related to the adhesive's ability to resist flaw propagation, such as crack growth or peeling resistance from the substrate.

Many authors reported true interfacial failure with minimal cohesive fractures in enamel-dentine complex or resin. However, the reported mixed failure modes are often not describing the percentage of cohesive failure and within which material (enamel-dentine complex, adhesive resin or restorative material) (21); because, if large cohesive failures within dentin or resin can be evaluated with a stereomicroscope at low magnification, the decision on the mode of failure for the adhesive interface or mixed failures can only be properly made using a Scanning Electron Microscope at high magnification $(37,38)$.

When the SEM images were analyzed, adhesive failures were the most frequent fracture pattern $(53.3 \%)$ and were more likely to occur between the tooth substrate and ceramic rather than between resin cement and ceramic.

Furthermore, the SEM analyses demonstrated that most of the dentinal tubules were covered with the dentine adhesives. Therefore, it can be assumed that dentine adhesives sufficiently penetrated into the dentinal tubules even under a ceramic restoration as seen in (Fig.3 a, b).

This type of failure has also been observed in a study in the dental literature by Akgungor et. al (39) where SEM analysis revealed adhesive failures at the hybrid layer adhesive interface, indicating a bond to dentin that was lower than the cohesive strength of the resin luting agent.

\section{CONCLUSIONS}

Within the limitations of this study, the following conclusions can be addressed:

1. The type of tooth structure - Enamel and Enamel-Dentine complex - affected the shear bond strength of the ceramic laminate veneers.

2. It should be avoided that the ceramic laminate veneer restoration is bonded only to dentine, since shear bond strength was the lowest on enamel-dentine complex.

3. The type of resin cements - dual-cure or light-cure-did not affect the shear bond strength of the ceramic laminate veneer restorations.

\section{CONFLICT OF INTREST}

The authors declare that they have no conflicts of interest.

\section{REFERENCES}

1. Peumans M, Van Meerbeek B, Lambrechts P, Vanherle G. Porcelain yeneers: A review of the literature. J Dent 2000; 28:163-77.

2. Peumans M, Van Meerbeek B, Yoshida Y, Lambrechts P, Vanherle G. Porcelain veneers bonded to tooth structure: an ultra-morphological FE SEM examination of the adhesive interface. Dent Mat 1999;15: 105-19.

3. Zarone F, Epifania E, Leone G, Sorrentino R, Ferrari M. Dynamometric assessment of the mechanical resistance of porcelain veneers related to tooth preparation: a comparison between two techniques. J Prosthetic Dent 2006; 95: 35463.

4. Rouse JS, Robbins JW. Porcelain veneers. In: Summitt JB, Robbins JW, Hilton TJ, Schwartz RS, editors. Fundamentals of operative dentistry: a contemporary approach. 3rd ed. Chicago: Quintessence Publishing Co, Inc 2006; 463-87.

5. Omar H, Atta O, El-Mowafy O, Khan SA. Effect of CADCAM porcelain veneers thickness. on their cemented color. J Dent 2010; 38: 95-9.

6. Troedson M, Derand T. Shear stresses in the adhesive layer under porcelain veneers. A finite element method study. Acta Odontol Scand 1998; 56: 257-62.

7. Sadowsky SJ. An overview of treatment considerations for esthetic restorations: a review of the literature. J Prosthetic Dent 2006; 96:433-42.

8. Lin TM, Liu PR, Ramp LC, Essig ME, Givan DA, Pan YH. Fracture resistance and marginal discrepancy of porcelain 
laminate veneers influenced by preparation design and restorative material in vitro. J Dent 2012; 40: 20-29.

9. Brunton PA, Richmond S, Wilson NH. Variations in the depth of preparations for porcelain laminate veneers. Eur J Prosthodont Restor Dent 1997; 5: 89-92.

10. Nattress BR, Youngson CC, Patterson CJ, Martin DM, Ralph JP. An in vitro assessment of tooth preparation for porcelain veneer restorations. J Dent 1995; 23: 165-70.

11. Van Meerbeek B, Perdigao J, Lambrechts P, Vanherle G. The clinical performance of adhesives. J Dent 1998; 26: 120.

12. Xing W, Jiang T, Ma X, Liang S, Wang Z, Sa Y, et al. Evaluation of the esthetic effect of resin cements and try-in pastes on ceromer veneers. J Dent 2010; 38: e87-e94.

13. Stangel I, Ellis TH, Sacher E. Adhesion to tooth structure mediated by contemporary bonding systems. Dent Clin North Am 2007; 51:677-94.

14. De Munck J, Van Landuyt K, Peumans M, Poitevin A, Lambrechts P, Braem M, et al. A critical review of the durability of adhesion to tooth tissue: methods and results. J Dental Res 2005; 84: 118-32.

15. Ozturk E, Hickel R, Bolay S, Ilie N. Micromechanical properties of veneer luting resins after curing through ceramics. Clin Oral Investig 2012; 16: 139-46.

16. ALGhazali N, Laukner J, Burnside G, Jarad FD, Smith PW, Preston AJ. An investigation into the effect of try-in pastes, uncured and cured resin cements on the overall color of ceramic veneer restorations: an in vitro study. J Dent 2010; 38: e78-86.

17. Turgut S, Bagis B. Colour stability of laminate veneers: an in vitro study. J Dent 2011; 39: e57-64.

18. Perdigao J. Dentin bonding as a function of dentin structure. Dent Clin North Am 2002; 46:277-301.

19. Pekkan G, Hekimoglu C. Evaluation of shear and tensile bond strength between dentin and ceramics using dualpolymerizing resin cements. J Prosthetic Dent 2009; 102: 242-52.

20. Ozturk E, Bolay S, Hickel R, Ilie N. Shear bond strength of porcelain laminate to enamel, dentine and enamel - dentine complex bonded with different adhesive luting systems. J Dent. 2013; 41:97-105.

21. Scherrer SS, Cesar PF, Swain MV. Direct comparison of the bond strength results of the different test methods: a critical literature review. Dent Mat 2010;26:78-93.

22. Kotz S, Balakrishnan N, Read CB, Vidakovic B. Encyclopedia of statistical sciences. 2nd ed. Hoboken, N.J.: Wiley-Interscience; 2006.

23. Kirkpatrick LA, Feeney BC. A simple guide to IBM SPSS statistics for version 20.0. Student ed. Belmont, Calif.: Wadsworth, Cengage Learning; 2013.

24. Lee JJ, Nettey-Marbell A, Cook Jr A, Pimenta LA, Leonard R, Ritter AV. Using extracted teeth for research: the effect of storage medium and sterilization on dentin bond strengths. The Journal of the American Dental Association 2007;138:1599-603.
25. Della Bona A, van Noort R. Shear vs. tensile bond strength of resin composite bonded to ceramic. Journal of Dental Research 1995; 74(9):1591-6.

26. Rosenstiel SF, Land MF, Crispin B. Dental luting agents: A review of the current literature. J Prosthet Dent. 1998; 80:280-301.

27. Kelly JR, Campbell SD, Bowen HK. Fracture-surface analysis of dental ceramics. J Prosthet Dent 1989; 62: 53641.

28. Abo-Hamar SE, Hiller KA, Jung H, Federlin M, Friedl KH, Schmalz G. Bond strength of a new universal self-adhesive resin luting cement to dentin and enamel. Clinical Oral Investigations 2005;9:161-7.

29. Bair J, Bhatt S, Perry R, Kugel G. Shear bond strength of resin cements to dentin and enamel. J Dent Res 2013, 92 (Spec Iss A): 3042.

30. Chiba Y, Rikuta A, Yasuda G, Yamamoto A, Takamizawa $\mathrm{H}$, Ando S, et al. Influence of moisture conditions on dentin bond strength of single-step self-etch adhesive systems. J Oral Sci 2006; 48: 131-7.

31. Lafuente JD, Chaves A, Carmiol R. Bond strength of dualcured resin cements to human teeth. J Esthet Dent 2000; 12 : 105-10.

32. Hikita K, Van Meerbeek B, De Munck J, Ikeda T, Van Landuyt K, ve digerleri MT. Bonding effectiveness of adhesive luting agents to enamel and dentin. Dent Mat 2007;23:71-80.

33. Pekkan G, Hekimoglu C. Evaluation of shear and tensile bond strength between dentin and ceramics using dualpolymerizing resin cements. Journal of Prosthetic Dentistry 2009;102:242-52.

34. Eick JD, Gwinnett AJ, Pashley DH, Robinson SJ. Current concepts on adhesion to dentin. Critical Reviews of Oral Biology \& Medicine 1997;8:306-35.

35. Rouse JS, Robbins JW. Porcelain veneers. In: Summitt JB, Robbins JW, Hilton TJ, Schwartz RS, editors. Fundamentals of operative dentistry: a contemporary approach. 3rd ed. Chicago: Quintessence Publishing Co, Inc 2006; 463-87.

36. Magne P, Douglas WH. Porcelain veneers: dentin bonding optimization and biomimetic recovery of the crown. International Journal of Prosthodontics 1999;12:111-21.

37. Armstrong SR, Boyer DB, Keller JC. Micro-tensile bond strength testing and failure analysis of two dentin adhesives. Dent Mat 1998;14:44-50.

38. Cho BH, Dickens SH. Effects of the acetone of single solution dentin bonding agents on the adhesive layer thickness and the micro-tensile bond strength. Dent Mat 2004;20:107-15.

39. Akgungor G, Akkayan B, Gaucher H. Influence of ceramic thickness and polymerization mode of a resin-luting agent on early bond strength and durability with a lithium disilicate-based ceramic system. Journal of Prosthetic Dentistry 2005;94:234-41. 